\title{
RELAÇÃO DE VARIÁVEIS AMBIENTAIS EM BAIAS COBERTAS COM POLIETILENO E DESEMPENHO DA RÃ-TOURO (Rana catesbeiana)
}

\author{
SÔNIA M. TEODORO ${ }^{1}$, MODESTO A. CHAVES ${ }^{2}$, JOÃO F. ESCOBEDO ${ }^{3}$, \\ CLÁUdiO A. AGOSTINHO
}

\begin{abstract}
RESUMO: Este trabalho visou a relacionar variáveis ambientais em instalação para criação de rãs, com cobertura de polietileno e baias construídas usando material alternativo, com o desempenho de rãs-touro (Rana catesbeiana). No interior das baias, foram medidas as temperaturas do piso, do ar ambiente (bulbo seco), de bulbo úmido, globo negro e da água do reservatório. Foram utilizados 60 animais por baia e três baias por galpão. As variáveis de desempenho estudadas foram peso vivo, ganho de peso e conversão alimentar. Nas condições experimentais, quando a temperatura do ar atingiu valores abaixo de $10{ }^{\circ} \mathrm{C}$ ou superiores a $40{ }^{\circ} \mathrm{C}$, houve diminuição no consumo de ração pelos animais. Concluiu-se que o estresse predominante, neste tipo de estrutura, para as condições climáticas do período experimental, foi devido, principalmente, às baixas temperaturas. Concluiu-se, ainda, que o uso do Índice de Temperatura e Umidade (THI), na estimativa de variáveis de desempenho, melhorou a precisão da estimativa em relação ao uso exclusivo da temperatura do ar, embora valores desse índice, considerados estressantes para animais superiores, não o tenham sido para as rãs.
\end{abstract}

PALAVRAS-CHAVE: ambiência, instalações zootécnicas, índices bioclimáticos.

\section{RELATIONSHIP BETWEEN ENVIRONMENTAL VARIABLES IN SHEDS COVERED WITH A POLYETHYLENE STRUCTURE AND THE PERFORMANCE OF BULLFROGS (Rana catesbeiana)}

\begin{abstract}
The objective of this project was to find correlations between environmental variables of an installation used for raising frogs and the performance of the Bullfrog (Rana catesbeiana). Each installation included a shed built with alternative materials covered by a polyethylene structure. Floor, air (dry bulb), wet bulb, black globe and swimming water temperatures were measured inside the sheds. Sixty bullfrogs were raised in each shed with three sheds in each structure. The performance variables studied, included live weight, weight gain and food conversion. A decrease in food consumption was observed each time air temperatures fell below $10{ }^{\circ} \mathrm{C}$ or went above $40{ }^{\circ} \mathrm{C}$. It was concluded that the main stress factor in this kind of structure and these climatic conditions during the experimental period was due to low temperatures. It was also concluded that the use of the Temperature and Humidity Index (THI) in estimating performance variables improved estimation accuracy when compared with the exclusive use of air temperatures although index values considered to be stressful for higher species were not for the frogs.
\end{abstract}

KEYWORDS: animal environment, animal shelter, bioclimatic indexes.

\footnotetext{
${ }^{1}$ Zootecnista, Prof. Adjunta, DEBI, UESB, Itapetinga - BA, Fone: (0XX77) 261.8628, ppgit@uesb.br

${ }^{2}$ Eng $^{\text {o }}$ Agrícola, Prof. Adjunto, DEBI, UESB, Itapetinga - BA.

${ }^{3}$ Físico, Prof. Adjunto, DRN, FCA-UNESP, Botucatu - SP.

${ }^{4}$ Zootecnista, Prof. Adjunto, DPEA, FMVZ, UNESP, Botucatu - SP.

Recebido pelo Conselho Editorial em: 28-5-2003

Aprovado pelo Conselho Editorial em: 18-2-2005
} 


\section{INTRODUÇÃO}

Segundo FIGUEIREDO (1996), as instalações para criação de rãs ainda necessitam de resultados experimentais para definir um padrão de construção que promova o melhor conforto térmico. A tecnologia para criação desses animais necessita de informações a respeito das relações da rã com o ambiente e, principalmente, das situações em que se obtêm os melhores desempenhos.

Estudos envolvendo coberturas plásticas para instalações animais são relativamente recentes. HOLLMANN (1998) conduziu trabalhos a fim de determinar o perfil térmico de dois tipos de baias de recria sobrepostas com dois tipos de cobertura (plástica e de fibrocimento) e concluiu que as baias com cobertura plástica apresentaram valores de temperatura do ar ambiente, no interior dos abrigos e na água das piscinas, mais elevados e próximos do que parece ser o ideal para os animais, que seriam entre 27 e $29^{\circ} \mathrm{C}$, de acordo com FIGUEIREDO (1996).

ROSEMBERG (1983) indica os valores do Índice de Temperatura e Umidade (THI) até 70 como zona de conforto para os animais superiores e até 75 como zona suportável sem perdas na produção. Contudo, não se conseguiu encontrar valores desse índice específico para a rã-touro.

TANAKA \& XIN (1997) destacam que, mesmo nos países de primeiro mundo, as modernas construções com ambiente controlado requerem alto investimento de capital. Segundo esses pesquisadores, os produtores encaram o desafio de reduzir os custos de construção, sem sacrificar a qualidade ambiental. TEODORO (2001) faz uma ampla revisão sobre o tema e afirma que a cobertura plástica se torna uma alternativa atrativa, particularmente para produtores que enfrentam incertezas quanto à produção, a longo prazo, ou quanto à implantação de uma cultura. Ainda de acordo com esse autor, observa-se atualmente, no Brasil, a utilização de estufas com coberturas plásticas por parte de muitos criadores, com o objetivo de minimizar os efeitos climáticos, porém, até o presente, poucos resultados satisfatórios têm sido relatados.

Este trabalho visou a relacionar as variáveis ambientais em três instalações para criação de rãs, que utilizaram cobertura plástica de polietileno (de três cores: branca, transparente e verde) e baias construídas com material alternativo, com o desempenho de rãs-touro (Rana catesbeiana). Também se avaliou o desempenho dos animais produzidos em baias onde se manteve a temperatura do ar superior a $27{ }^{\circ} \mathrm{C}$ e fotoperíodo de $12 \mathrm{~h}$.

\section{MATERIAL E MÉTODOS}

As estufas para criação de rãs foram montadas na área experimental do Setor de Ranicultura da FMVZ-UNESP de Botucatu (latitude 22 $2^{\circ} 2^{\prime} \mathrm{S}$, longitude $48^{\circ} 27^{\prime} \mathrm{W}$, altitude $815 \mathrm{~m}$ ); MARTINS (1996) verificou que o clima predominante no município, segundo os critérios adotados por Köeppen, é Cfa, clima mesotérmico (temperado), região constantemente úmida, tendo quatro ou mais meses com temperaturas médias superiores a $10{ }^{\circ} \mathrm{C}$, cuja temperatura do mês mais quente é igual ou superior a $22{ }^{\circ} \mathrm{C}$, índice médio pluviométrico anual de $1.516,8 \mathrm{~mm}$.

Foram construídos três galpões com diferentes tipos de cobertura plástica de polietileno, com $0,1 \mathrm{~mm}$ de espessura, nas colorações branca, transparente e verde, com dimensões de $6 \mathrm{~m}$ x 4,5 $\mathrm{m}$ x 3 $\mathrm{m}$, com pilares de madeira e estrutura do telhado com tubos metálicos em arco.

Dentro de cada galpão, foram colocadas três baias para criação (Figura 1), construídas com material alternativo (caixas de fibrocimento de $750 \mathrm{~L}$ ). As tampas dessas baias foram feitas de quadros de madeira com tela de sombreamento (bloqueando 30\% da luz solar). Foi colocada, em cada tampa, uma lâmpada incandescente $(15 \mathrm{~W}, 220 \mathrm{~V})$ usada, quando necessário, na complementação do fotoperíodo nos galpões. 
No laboratório, baias semelhantes receberam tampa de madeira opaca, com o propósito de isolamento térmico e de evitar a entrada de luz exterior. Essas baias, além das lâmpadas para estabelecimento de fotoperíodo, possuíam controle do nível mínimo de temperatura, por meio de aquecimento do piso.

No interior das baias (caixas de fibrocimento), mediram-se, com o uso de termopares, a temperatura do piso, do ar ambiente (bulbo seco), de bulbo úmido, de globo negro, e a temperatura da água da piscina. A umidade relativa do ar de cada baia foi, portanto, calculada a partir da depressão psicrométrica. Para medir a temperatura de globo negro, sensores de temperatura (pt 107 Temperature Prove - Campbell Instruments) foram inseridos em globos negros (C\&M Meteorological Supply). Na Figura 2, mostram-se os sensores utilizados nas baias de criação.
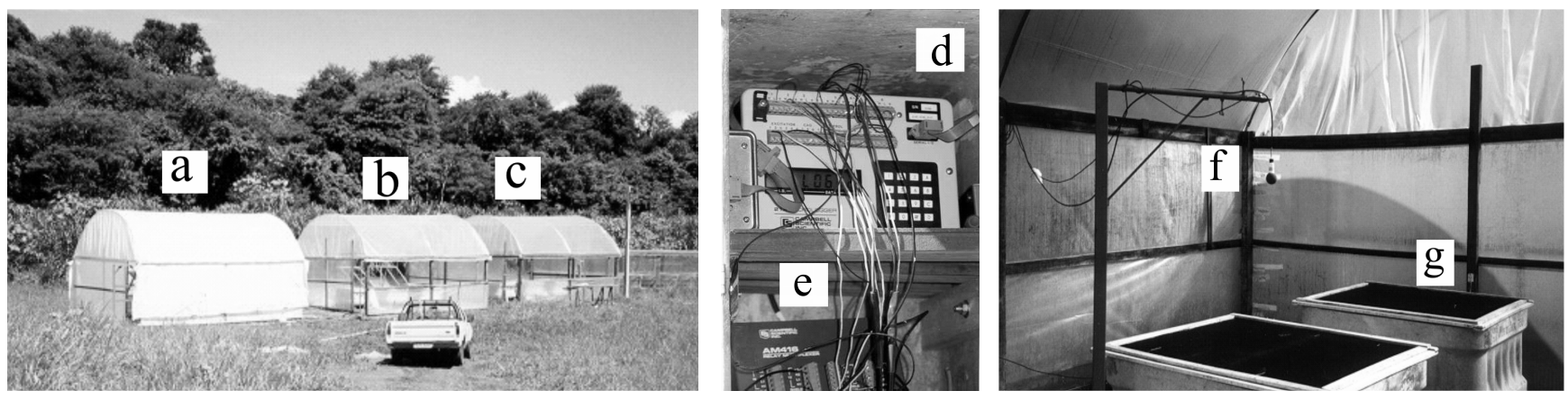

FIGURA 1. Estufas, sistema de coleta de dados e baias internas às estufas. (a) cobertura branca; (b) cobertura transparente; (c) cobertura verde; (d) datalogger; (e) multiplexadora; (f) globo negro externo às baias; (g) tela de sombreamento.
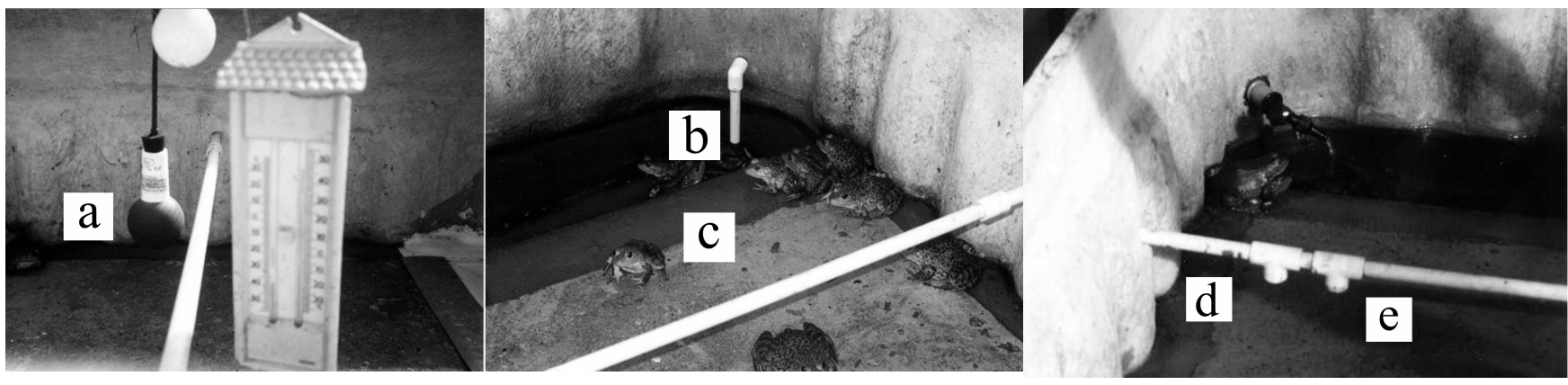

FIGURA 2. Disposição de alguns sensores nas baias. (a) temperatura de globo negro; (b) temperatura da água; (c) temperatura do piso; (d) temperatura de bulbo úmido; (e) temperatura de bulbo seco.

$\mathrm{Na}$ coleta de dados, utilizou-se de um datalogger (21X Campbell Instruments) e de placa multiplexadora (AM416 Relay multiplexer - Campbell Instruments). O sistema operou na freqüência de $0,03 \mathrm{~Hz}$ (duas leituras de todos os canais a cada minuto) e armazenando, de forma definitiva, a média dos dados de 5 minutos (24 leituras de cada canal). Os dados foram transferidos semanalmente a um computador, para gravação em disco.

Foi computado, ao longo do experimento, quanto tempo a temperatura esteve acima de 5; 10; 15 ; $20 ; 25 ; 30 ; 35 ; 40$ e $45{ }^{\circ} \mathrm{C}$, em cada dia. Por conseqüência, também se obteve o tempo em que a temperatura foi menor ou igual a esses valores. Os valores acumulados desses tempos também foram registrados para os períodos entre as pesagens. Computou-se, também, o número de horas diárias em que o THI esteve superior a 75 em cada baia. 
Sob o aspecto da produção animal, os estudos concentraram-se nas fases de crescimento (imagos) e engorda (acima de $40 \mathrm{~g}$ até o peso comercial de $180 \mathrm{~g}$ ) da rã-touro.

De uma população inicial de 3.000 animais, foram selecionados 1.020, no início do experimento, com peso na faixa de 6-10 g. Antes de colocar os animais nas baias, cada um foi marcado, conforme marcação padrão (MARTOF, 1953) feita por amputação dos dedos e artelhos.

Cada estufa recebeu 255 animais ( 85 por baia, três baias por estufa), destinados às análises de desempenho. No laboratório, foram instaladas três baias como grupo-controle para os aspectos ambientais e parâmetros produtivos dos animais. Essas baias receberam manejo e número idêntico de animais ao das localizadas dentro das estufas, sendo mantido um nível mínimo de temperatura de $27 \pm$ $1{ }^{\circ} \mathrm{C}$, medidos a $15 \mathrm{~cm}$ acima da área seca da baia. $\mathrm{O}$ fotoperíodo foi mantido em $12 \mathrm{~h}$.

Durante a realização do experimento, realizaram-se dois descartes, eliminando-se os animais de pior desempenho e/ou que apresentassem quaisquer outros problemas, adequando-se a densidade. Procedeu-se o primeiro descarte ao final do primeiro mês de experimento, com redução da população para 70 animais por baia; no segundo descarte, ao final do segundo mês, eqüalizaram-se as baias para 60 animais.

Ao longo do experimento, os animais foram pesados individualmente. As pesagens ocorreram no início do experimento e em intervalos de aproximadamente 30 dias. Após cada pesagem, calcularam-se a média, a mediana e o desvio-padrão do peso dos indivíduos de cada grupo. Essas pesagens serviram como referência para os descartes do primeiro e segundo meses (descartando-se os animais com menores pesos).

$\mathrm{Na}$ análise de desempenho, o delineamento experimental foi inteiramente casualizado, sendo empregada, na avaliação dos resultados, a análise de perfil (multivariada), com quatro grupos (três tratamentos e um controle), em sete momentos. Testou-se a interação grupo-condição pelos pontos de mais alta porcentagem da distribuição da maior raiz característica de matrizes aleatórias encontradas em análise multivariada, conforme a metodologia usada por TEODORO (1998). As variáveis de desempenho analisadas dessa forma foram peso vivo e ganho de peso. Após aceitação ou rejeição da hipótese de paralelismo dos perfis, procederam-se às análises pertinentes pela estatística “T2" de Hotelling ou pela distribuição de F, seguida da construção de intervalos de confiança, conforme o desdobramento da análise assim o exigisse. Também foram computados os dados de consumo e conversão alimentar.

Foram estabelecidas correlações entre variáveis ambientais e variáveis de desempenho, estabelecendo-se os níveis de significância pelo teste " $\mathrm{t}$ ". Correlacionando-se valores médios, máximos e mínimos acumulados do THI e o peso vivo e ganho de peso dos animais.

\section{RESULTADOS E DISCUSSÃO}

Na Figura 3, estão traçadas as curvas referentes aos dados de peso vivo médio (gramas) para todos os tratamentos durante o período experimental. Observou-se que até a terceira pesagem (55 dias após o início do experimento), todos os tratamentos apresentaram pesos similares. A partir desse momento, os animais do laboratório (sob condições ambientais relativamente controladas) destacaram-se em relação aos demais animais, mantidos em estufas com cobertura de polietileno.

A análise multivariada não rejeitou a hipótese de paralelismo dos perfis $(\mathrm{p}<0,01)$. Pela distribuição $\mathrm{F}$, a hipótese de perfis coincidentes foi rejeitada $(\mathrm{p} \geq 0,01)$, indicando que os perfis, embora análogos, não puderam ser considerados coincidentes. De posse desse resultado, estabeleceram-se intervalos de confiança para os contrastes entre grupos. Na Tabela 1, apresenta-se um 
resumo dessa análise, sendo que o tratamento-controle (laboratório) diferiu de todos os outros $(\mathrm{p}<0,01)$. Numa comparação entre tratamentos, apenas para o contraste entre a cobertura transparente e a branca, detectou-se diferença significativa pelo teste de $\mathrm{F}(\mathrm{p}<0,01)$.

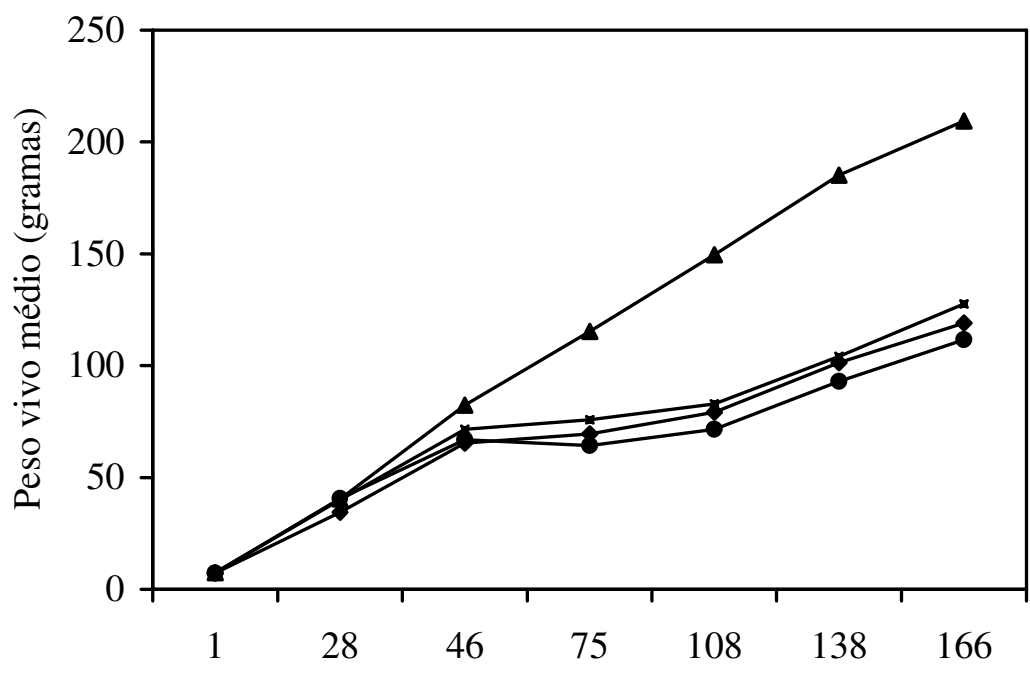

Dias após o experimento

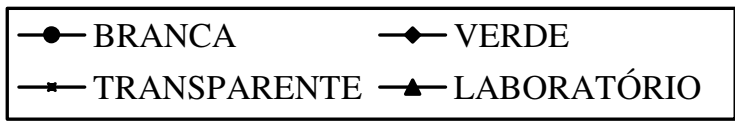

FIGURA 3. Peso vivo médio dos animais, em função do momento de avaliação.

TABELA 1. Intervalos de confiança para o peso vivo dos animais de cada tratamento.

\begin{tabular}{lccc}
\hline \multirow{2}{*}{ Contraste } & \multicolumn{2}{c}{ Limites do Intervalo } & \multirow{2}{*}{ Conclusão } \\
\cline { 2 - 3 } & Superior & Inferior & \\
\hline Verde-Branca & 92,987 & $-13,513$ & Não diferem * \\
Transparente-Branca & 128,060 & 19,689 & Diferem \\
Transparente-Verde & 108,324 & $-39,426$ & Não diferem \\
Laboratório-Branca & 407,850 & 260,099 & Diferem \\
Laboratório-Verde & 388,114 & 240,363 & Diferem \\
Laboratório-Transparente & 353,665 & 205,914 & Diferem \\
\hline
\end{tabular}

* Intervalos de confiança estabelecidos com $99 \%$ de probabilidade pelo teste de Scheffé

Nas condições climáticas de Botucatu, para o período experimental, a estufa com cobertura transparente foi a que apresentou maiores valores de peso médio, provavelmente por armazenar energia para manter o ambiente mais aquecido no período noturno e por não atingir, durante o dia, temperaturas tão altas quanto a estufa verde. Contudo, apenas se detectou diferença estatística ( $\mathrm{p}<0,01$ ), no que se refere a esta variável, entre essa cobertura e a cobertura branca. Possivelmente, a razão para não se ter detectado diferenças estatísticas entre os perfis, está nos três primeiros dados de pesagem, quando as condições ambientais estiveram relativamente boas em todas as coberturas, tendo sido observadas médias das mínimas de $17,0{ }^{\circ} \mathrm{C}$ e média geral de $25,0{ }^{\circ} \mathrm{C}$ para as três estufas. A média das máximas foi de $38,0{ }^{\circ} \mathrm{C}$ para a estufa branca e de $45,0{ }^{\circ} \mathrm{C}$ para as estufas transparente e verde. Porém, quando o ambiente se tornou potencialmente estressante, a partir da quarta pesagem (75 dias de experimento), observaram-se sempre maiores valores de peso vivo para a estufa transparente do que para a verde e, nessa, valores maiores do que a branca. 
Não se conseguiu, pela análise multivariada, detectar diferença no ganho de peso médio entre as coberturas de polietileno, sendo que o tratamento-controle (laboratório) diferiu de todos os outros ( $\mathrm{p}<0,01)$. No teste do efeito dos momentos para o conjunto dos grupos, como era de se esperar, todos os contrastes entre momentos foram significativos pelo teste $\mathrm{F}(\mathrm{p}<0,01)$. Essa última análise apenas complementou o teste, uma vez que a inexistência de interação implicaria estabilização do crescimento ou perda de peso muito significativa.

Na Figura 4, apresenta-se o ganho de peso médio dos animais durante o experimento; os valores dessa variável apresentaram um pico durante a primeira fase experimental (até 46 dias do início do experimento). No período subseqüente, observou-se perda de peso, sendo essa pequena para os animais de laboratório. Essa perda coincidiu com a entrada do período de dias mais frios, podendo ser atribuída, possivelmente, ao período de adaptação dos animais. Observou-se que, no quinto momento de avaliação, o ganho apresentou incremento em seus valores, coincidindo esse aumento com o fim do inverno. Observou-se, ainda, que após o período de perda de peso, inicial, os animais criados nas estufas apresentaram taxas de ganho de peso (recuperação) maiores que os do laboratório. Essa é uma característica que normalmente ocorre no período pós-estresse, colaborando com a hipótese de essa ter sido a causa da perda de peso.

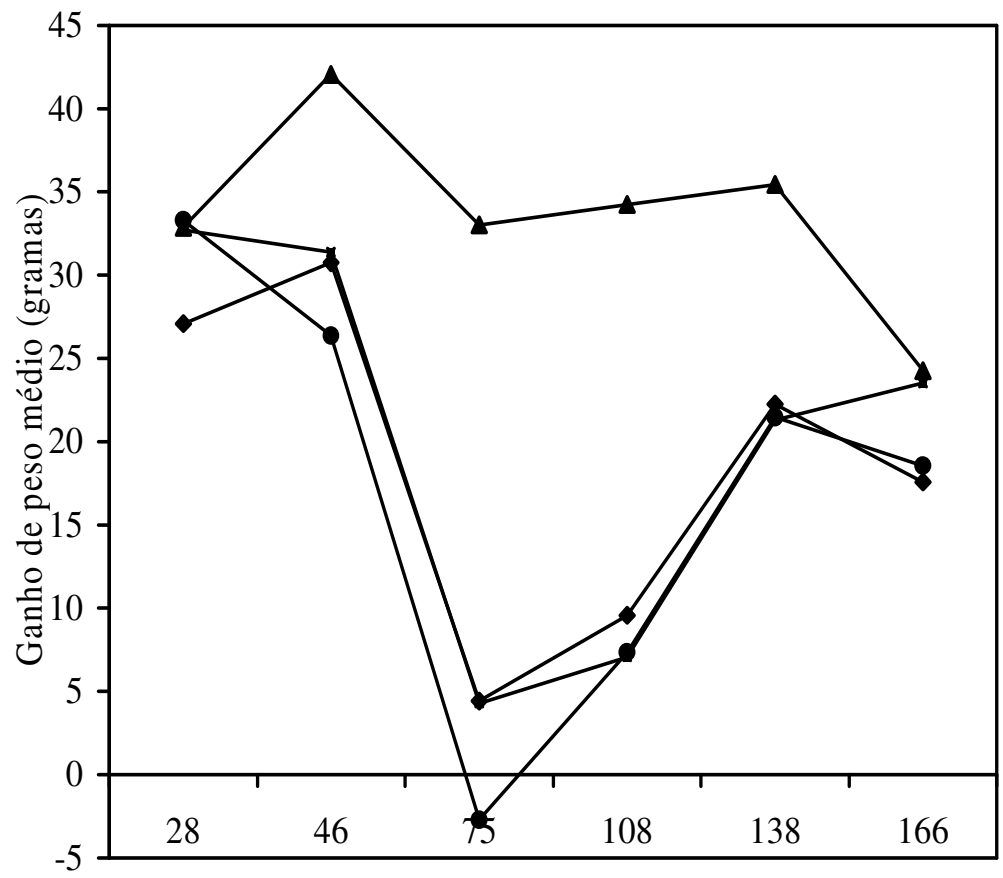

Dias após início do experimento

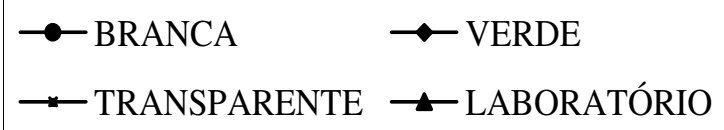

FIGURA 4. Ganho de peso médio, em função do momento de avaliação.

Os ganhos de peso médios observados neste trabalho foram próximos aos obtidos por LIMA \& AGOSTINHO, 1988 (0,91 $\left.\mathrm{g} \mathrm{dia}^{-1}\right)$, BARBALHO, 1991 (0,61 $\left.\mathrm{g} \mathrm{dia}^{-1}\right)$ e FONTANELLO et al., 1993 $\left(0,94 \mathrm{~g} \mathrm{dia}^{-1}\right)$, no caso dos animais criados nas estufas (verde $=0,73 \mathrm{~g} \mathrm{dia}^{-1}$; transparente $=0,78 \mathrm{~g} \mathrm{dia}^{-1}$; branca $=0,67 \mathrm{~g} \mathrm{dia}^{-1}$ ), sendo que os animais do grupo-controle (laboratório $=1,3 \mathrm{~g} \mathrm{dia}^{-1}$ ) apresentaram ganhos de peso bem mais altos que os obtidos por esses autores. Esses resultados mostram que a 
produção em estufas é viável, embora não produza ganhos de peso tão elevados como os da condição de controle da temperatura do piso.

Os resultados da comparação dos intervalos de confiança, para a variável ganho de peso, estão resumidos na Tabela 2 ; estes diferiram entre todos os tratamentos $(\mathrm{p}<0,01)$, mostrando clara influência das condições ambientais.

TABELA 2. Intervalos de confiança para o ganho de peso dos animais de cada tratamento.

\begin{tabular}{lccc}
\hline \multirow{2}{*}{ Contraste } & \multicolumn{2}{c}{ Limites do Intervalo } & \multirow{2}{*}{ Conclusão } \\
\cline { 2 - 3 } & Superior & Inferior & \\
\hline Verde-Branca & 31,386088 & 16,65922 & Diferem * \\
Transparente-Branca & 15,945004 & 5,94510 & Diferem \\
Transparente-Verde & 18,581570 & 8,58157 & Diferem \\
Laboratório-Branca & 97,630715 & 86,36072 & Diferem \\
Laboratório-Verde & 90,267281 & 78,45722 & Diferem \\
Laboratório-Transparente & 81,685711 & 81,68571 & Diferem \\
\hline
\end{tabular}

* Intervalos de confiança estabelecidos com $99 \%$ de probabilidade, pelo teste de Scheffé.

No teste da hipótese de não-existência de diferença entre os momentos, para o conjunto dos tratamentos, para o caso do ganho de peso, rejeitou-se a hipótese pelo teste $\mathrm{F}(\mathrm{p} \leq 0,01)$, evidenciando diferença entre os momentos.

Para os momentos de pesagem, a construção de intervalos de confiança em nível de $99 \%$ de probabilidade, pelo teste de Scheffé, na comparação da evolução temporal de cada tratamento, apontou como único contraste, no qual não se detectou diferença aquele entre o primeiro e o segundo momentos, o que pode, possivelmente, ser atribuído ao fato de as condições ambientais, no início do experimento, terem sido relativamente favoráveis, em todos os tratamentos. Todos os demais contrastes diferiram entre si, a 99\% de probabilidade, pelo teste de Scheffé.

Os animais do grupo-controle apresentaram consumos médios de ração crescentes ao longo do experimento, exceto no período final do experimento. Na Tabela 3, apresentam-se a média e o desviopadrão do consumo de ração (gramas), por animal, durante os momentos de avaliação. Esses dados também são apresentados na Figura 5.

Os dados de conversão alimentar observados (Figura 6) apresentam uma inconveniência zootécnica, uma vez que houve perda de peso para os animais mantidos nas estufas de polietileno de cor branca e verde. Os resultados negativos apresentados pela estufa branca, durante o terceiro momento de avaliação, podem ser explicados pelas baixas temperaturas do ar e da água que inibiram o consumo e conseqüentemente o ganho. Nesse período, observou-se que os animais preferiram permanecer na sombra ou na água do que visitar o cocho, o que pode ter ocasionado as perdas de peso e os baixos consumos de ração, gerando, assim, conversões alimentares negativas. Fato contrário sucedeu aos animais da estufa com cobertura de cor verde, na fase final do experimento, quando se registraram elevadas temperaturas do ar dentro dessa estufa. Em virtude dessas altas temperaturas, adotou-se, como manejo de rotina (a fim de garantir a sobrevivência dos animais expostos a temperaturas do ar superiores a $50{ }^{\circ} \mathrm{C}$ ), a rápida troca da água das baias, no período da tarde.

Sempre que a temperatura esteve abaixo de $5{ }^{\circ} \mathrm{C}$, nas estufas branca e transparente, o consumo foi menor que a média. No caso da estufa verde, a temperatura esteve abaixo de $5{ }^{\circ} \mathrm{C}$ apenas em dois dias e por 5 minutos, sendo que em um desses dias, o consumo foi abaixo da média e no outro $6 \%$ acima. 
TABELA 3. Média e desvio-padrão do consumo de ração (gramas) por animal durante os momentos de avaliação.

\begin{tabular}{ccccc}
\hline \multirow{2}{*}{$\begin{array}{c}\text { Tempo } \\
\text { (dias) }\end{array}$} & Estufa Branca & Estufa Transparente & Estufa Verde & Laboratório \\
\cline { 2 - 5 } 28 & $39,18 \pm 2,24$ & $37,25 \pm 3,86$ & $37,38 \pm 4,43$ & $39,58 \pm 2,62$ \\
55 & $38,19 \pm 5,29$ & $41,28 \pm 5,00$ & $43,23 \pm 3,45$ & $47,17 \pm 2,64$ \\
84 & $15,82 \pm 1,85$ & $24,75 \pm 3,52$ & $24,53 \pm 1,54$ & $62,64 \pm 5,92$ \\
117 & $14,92 \pm 3,63$ & $23,48 \pm 3,41$ & $24,80 \pm 4,12$ & $72,34 \pm 7,48$ \\
147 & $75,47 \pm 7,09$ & $61,18 \pm 5,60$ & $60,57 \pm 6,42$ & $72,00 \pm 6,04$ \\
175 & $50,86 \pm 2,05$ & $47,38 \pm 7,86$ & $53,34 \pm 6,07$ & $73,60 \pm 13,45$ \\
194 & $46,05 \pm 7,64$ & $34,37 \pm 7,73$ & $40,83 \pm 3,61$ & $42,82 \pm 6,34$ \\
\hline
\end{tabular}

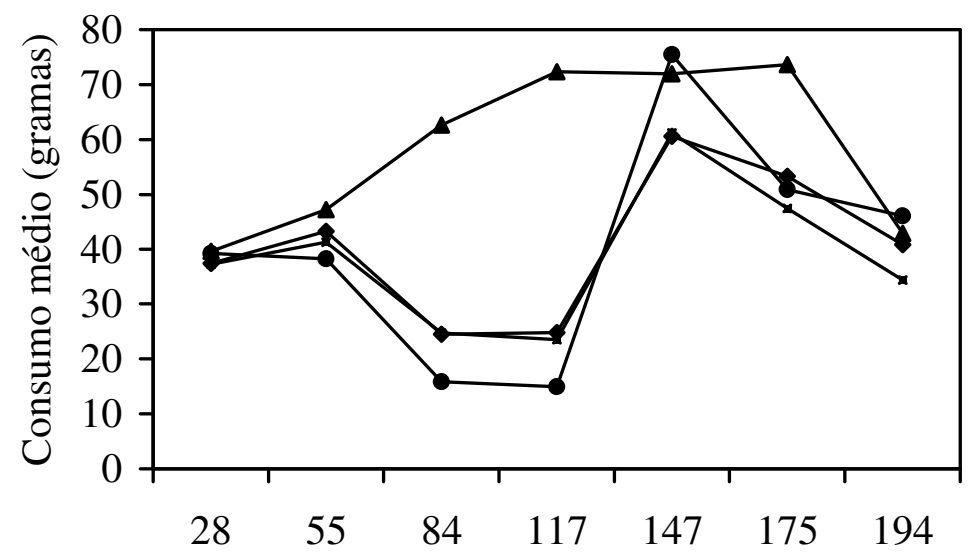

Dias após início do experimento

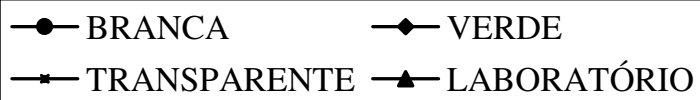

FIGURA 5. Consumo médio de ração ao longo do período experimental.

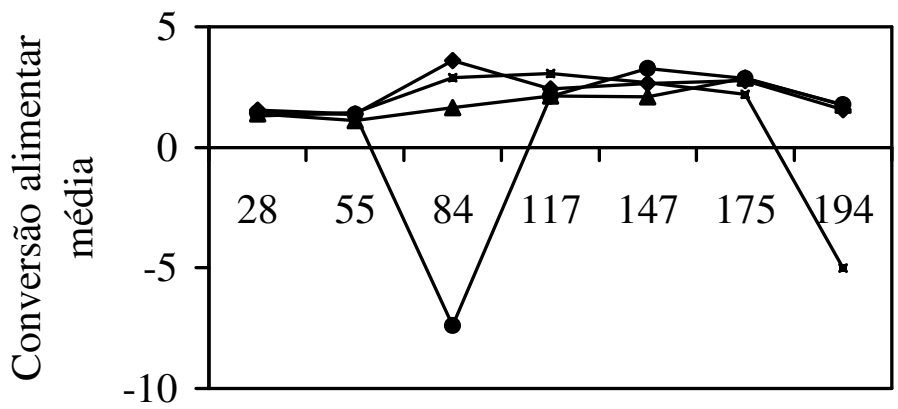

Dias após experimento

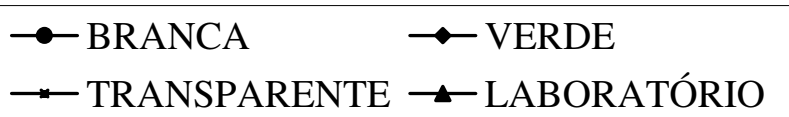

FIGURA 6. Conversão alimentar média durante o período experimental. 
A temperatura atingiu valores menores que $10{ }^{\circ} \mathrm{C}$ em um total de 29 dias na estufa branca e, em apenas dois desses dias, o consumo não foi menor que a média (93,7\% dos casos). Esses resultados são semelhantes ao das estufas transparente $(84,6 \%)$ e da estufa verde $(83,3 \%)$, o que indica claramente que o simples fato de a temperatura ter estado abaixo de $10{ }^{\circ} \mathrm{C}$ afetou o consumo.

Por outro lado, quando houve temperaturas superiores a $40{ }^{\circ} \mathrm{C}$ no interior da estufa branca, o consumo foi menor que a média em $86,7 \%$ dos casos. Para a estufa transparente, o consumo foi menor em $80 \%$ dos casos, o que indica que, pelo menos em relação ao consumo, nesses dias de maior temperatura, os animais estiveram estressados nessas estufas. Por outro lado, para a estufa verde, em apenas $13 \%$ dos casos, o consumo diminuiu. Porém, o número de dias com temperatura superior a $40{ }^{\circ} \mathrm{C}$, nessa cobertura, foi cerca de três vezes maior que o das outras, com um total de $125 \mathrm{~h}$ de temperatura acima de $40{ }^{\circ} \mathrm{C}$, contra $31,8 \mathrm{~h}$ para a estufa transparente e $17,7 \mathrm{~h}$ para a estufa branca. Esse tempo maior pode, possivelmente, ter permitido alguma adaptação dos animais.

Observou-se que o consumo, na estufa branca, diminuiu sempre que se passou de um período em que não ocorreram temperaturas maiores que $40{ }^{\circ} \mathrm{C}$ para uma ocorrência desse tipo, ou quando, numa seqüência de dias com temperaturas acima de $40{ }^{\circ} \mathrm{C}$, houve aumento do número de horas do dia em que a temperatura esteve acima desse nível, o que reforça a hipótese de que temperaturas acima de $40{ }^{\circ} \mathrm{C}$ diminuíram o consumo, salvo quando houve um período de adaptação.

Não se encontraram boas correlações entre as temperaturas máxima, mínima, média e a amplitude térmica diária com o consumo de ração.

A temperatura média diária foi a que apresentou maiores valores de correlação com o consumo de ração, sendo esses valores de 39,4\%; 38,9\% e 44,0\% para as coberturas branca, transparente e verde, respectivamente. Essas baixas correlações mostram que a temperatura do ar, isoladamente, embora ofereça subsídios importantes, não é suficiente para uma modelagem do consumo.

No que se refere ao ganho de peso dos animais, observou-se que, a partir do terceiro momento de coleta, os animais do laboratório se destacaram daqueles nas estufas. A temperatura ambiente, mantida acima de $27{ }^{\circ} \mathrm{C}$ no laboratório, teve, muito provavelmente, influência.

$\mathrm{Na}$ Tabela 4, apresentam-se as correlações entre temperaturas máxima, mínima, média, amplitude térmica e consumo nos períodos entre as coletas de dados e os valores do peso vivo, no momento da coleta, e ganho de peso no período, para as três coberturas.

O consumo apresentou uma correlação de $75 \%$ com o ganho de peso $(\mathrm{p}<0,01)$, e as temperaturas média e mínima apresentaram $65 \%$ e $67 \%$ de correlação com essa variável, respectivamente $(\mathrm{p}<0,05)$. A temperatura mínima apresentou, ainda, $52 \%$ de correlação com o peso vivo, contra $61 \%$ do consumo $(\mathrm{p}<0,05)$. Esses resultados confirmam a importância da temperatura ambiente e a hipótese de o estresse ter sido mais acentuado devido ao frio.

Não se encontrou boa correlação entre as horas de THI menor que 75 com o ganho de peso ou com o peso vivo.

As correlações entre os valores médios, máximos e mínimos acumulados do THI e o peso vivo dos animais apresentaram valores menores que 70\%. A correlação entre os valores médios de THI e o ganho de peso foi a que apresentou melhores resultados. As equações de regressão obtidas, para esse caso, estão na Tabela 5.

O uso do THI, ao invés de apenas utilizar a temperatura do ar, melhorou as correlações obtidas em relação ao peso vivo e ao ganho de peso, e as melhores correlações encontradas, nesse caso, têm valor absoluto maior que o da correlação entre consumo acumulado e peso vivo, ou consumo médio e ganho de peso. 
TABELA 4. Correlações entre temperaturas máxima, mínima, média, amplitude média e consumo nos períodos entre as coletas de dados e valores do peso vivo no momento da coleta e ganho de peso no período, para as três coberturas.

\begin{tabular}{lccc}
\hline Comparação & Correlação & Teste t & Significância \\
\hline Temperatura média x peso vivo & 0,12 & 0,43 & 0,34 \\
Temperatura média x ganho de peso & 0,65 & 29304,00 & 0,01 \\
Consumo x peso vivo & 0,61 & 27759,00 & 0,01 \\
Consumo x ganho de peso & 0,75 & 40321,00 & 0,00 \\
Temperatura mínima x peso vivo & 0,52 & 16866,00 & 0,03 \\
Temperatura mínima x ganho de peso & 0,67 & 19171,00 & 0,02 \\
Temperatura máxima x peso vivo & $-0,29$ & $-10923,00$ & 0,15 \\
Temperatura máxima x ganho de peso & 0,29 & 10981,00 & 0,15 \\
Amplitude térmica x peso vivo & $-0,19$ & $-0,69$ & 0,25 \\
Amplitude térmica x peso vivo & 0,18 & 0,65 & 0,26 \\
\hline
\end{tabular}

TABELA 5. Equações de regressão encontradas para relacionar THI médio e ganho de peso.

\begin{tabular}{lcc}
\hline Grupo & Equação & $\mathrm{R}^{2}(\%)$ \\
\hline Branca & $\mathrm{Y}=0,33 \mathrm{X}+66,95$ & 93,4 \\
Transparente & $\mathrm{Y}=0,28 \mathrm{X}+67,23$ & 92,0 \\
Verde & $\mathrm{Y}=0,24 \mathrm{X}+66,96$ & 93,4 \\
\hline Laboratório & $\mathrm{Y}=0,28 \mathrm{X}+67,07$ & 92,0 \\
\hline
\end{tabular}

\section{CONCLUSÕES}

O tipo de estresse predominante, em estufas cobertas com polietileno, para as condições climáticas do período experimental, foi devido principalmente às baixas temperaturas.

Embora o consumo de ração possa ser usado como indicativo de estresse, esse não permitiu boa estimativa do peso vivo ou do ganho de peso, tendo sido o Índice de Temperatura e Umidade (THI) mais eficiente, nesse tipo de estimativa.

Valores extremos de temperatura do ar, embora tenham sido indicativos de queda de produção, per se, pouco contribuíram para a análise do desempenho, tendo sido fundamental a determinação do tempo de ocorrência desses valores.

Nas condições deste experimento, bastou a temperatura do ar ter caído abaixo de $10{ }^{\circ} \mathrm{C}$ ou ter atingido valores superiores a $40{ }^{\circ} \mathrm{C}$ para que houvesse diminuição no consumo de ração pela Rana catesbeiana.

O uso da variável temperatura do ar, isoladamente, não é suficiente para a modelagem do consumo de ração.

Os valores clássicos de THI, considerados estressantes, não se aplicaram às rãs; contudo, houve forte correlação entre os valores máximos acumulados de THI e o peso vivo, e entre os valores médios de THI e o ganho de peso, sendo que o uso deste índice, na estimativa dessas variáveis de desempenho, melhorou a precisão da estimativa em relação ao uso unicamente da temperatura do ar.

Os resultados obtidos apontaram para a necessidade de estabelecimento de índices climatológicos específicos para a Rana catesbeiana. 


\section{REFERÊNCIAS}

BARBALHO, O.J.M. Exigência de proteína bruta de rã-touro (Rana catesbeiana, Shaw 1802) na fase de terminação. 1991. 55 f. Dissertação (Mestrado em Nutrição de Monogástrico) - Universidade Federal de Viçosa, Viçosa - MG, 1991.

FIGUEIREDO, M.R.C. Influência dos fatores ambientais sobre o desempenho da rã-touro (Rana catesbeiana, Shaw 1802) em gaiolas. 1996. 151 f. Tese (Doutorado em Fisiologia Animal) Universidade Federal de Viçosa, Viçosa - MG, 1996.

FONTANELLO, D.; WIRZ, R.R.; SOARES, H.A.; FREITAS, E.N.; CAMPOS, B.E.S.; FERREIRA, C.M. Comparação de quatro sistemas de engorda de rã-touro (Rana catesbeiana, Shaw 1802): tanqueilha, confinamento, anfigranja e gaiolas. 1 - Desenvolvimento ponderal; 2 - Custo operacional. Boletim do Instituto de Pesca, São Paulo, v.20, único, p.43-58, 1993.

HOLLMANN, A. Perfil térmico de instalações do sistema anfigranja com diferentes alternativas construtivas para a criação da rã-touro (Rana catesbeiana). 1998. 94 f. Dissertação (Mestrado em Reprodução Animal) - Universidade Federal de Viçosa, Viçosa - MG, 1998.

LIMA, S.L.; AGOSTINHO, C.A. Anfigranja: sistema de criação intensiva de rãs. In: ENCONTRO NACIONAL DE RANICULTURA, 6., 1988. Rio de Janeiro. Anais... Rio e Janeiro: Associação dos Ranicultores do Estado do Rio de Janeiro, 1988. p.15-27.

MARTINS, D. Classificação climática de Botucatu e São Manuel. Botucatu: Departamento de Ciências Ambientais - Faculdade de Ciências Agronômicas, UNESP, 1996. 2 p.

MARTOF, B.S. Territoriality in the green frog (Rana clamimatans). Ecology, Tempe, v.34, n.1, p.16674, 1953.

ROSEMBERG, L.J.; BIAD, B.L.; VERNS, S.B. Human and animal biometeorology. In: Microclimate - the biological environment. $2^{\text {nd }}$ ed. New York: Wiley-Interscience, 1983. cap.2, p.42567.

TANAKA, A.; XIN, H. Thermal characteristics of a hoop structure for swine production. Transactions of the ASAE, St. Joseph, v.4, n.40, p.1171-7, 1997.

TEODORO, S.M. Desempenho e morfologia intestinal de leitões alimentados com dietas farelada ou extrusada seca e úmida. 1998. 79 f. Dissertação (Mestrado em Produção Animal)- Universidade Estadual Paulista, Botucatu, 1998.

TEODORO, S.M. Fatores ambientais na produção e em alguns aspectos histoquímicos e fisiológicos da rã-touro (Rana catesbeiana, Shaw 1802) criada em baias com cobertura de polietileno 2001. $209 \mathrm{f}$. Tese (Doutorado em Energia na Agricultura) - Universidade Estadual Paulista, Botucatu, 2001. 